\title{
New Year's Greeting
}

\author{
James V. Byrne
}

Received: 12 October 2009 / Accepted: 12 October 2009/Published online: 5 November 2009

(C) Springer-Verlag 2009

The year 2009 will be remembered as a year of financial instabilities and a potentially devastating flu pandemic. The former's fallout for scientists and physicians is still difficult to predict, and like most professionals not working in financial institutions, we can only hope that the longterm effects will not be too unsettling. To be sure, we will not be immune from the crisis, and it could yet affect how we practice neuroradiology over the next few years.

For this journal, however, it has been a good year with continued improvements in our editorial process, the Journal's impact factor, and the volume and quality of submissions. A long-standing ambition of the editors has been the introduction of regular review articles which highlight new areas of interest. Their subjects may be straightforward technical advances which open the way to improve our clinical services or more complex medicopolitical or medico-ethical issues.

In the next few months (beginning with the January 2010 issue), we will be producing themed issues. The subjects for these issues have been selected by the Section Editors and intend to bridge the gap between letters which highlight factors likely to change our practices and research papers. A series of review articles has also been commissioned, and the editors hope they will provide a varied diet for regular readers and remain a useful reference resource for all subscribers.

A journal such as Neuroradiology should be a vehicle by which readers debate current controversies. One loss has been a steady decline in the number of Letters-to-theEditor. The reasons are probably many, but I suspect the immediacy and ease of email circulation of short comments and ideas amongst smaller interest groups has replaced the letter as a means of raising such issues and seeking comments from colleagues. Nonetheless, I would encourage you to submit letters on subjects that challenge the status quo. Comments, however short, are quickly available to a wide readership because electronic publication in advance of print issues means that accepted submissions are currently only taking three weeks to be published online. We look forward to hearing from you. On behalf of all the Editors, I wish you a happy and prosperous 2010.

JV Byrne, Editor-in-Chief
J. V. Byrne $(\bowtie)$

Department of Neuroradiology, John Radcliffe Hospital, Level-West Wing, Headley Way,

Oxford OX3 9HE, UK

e-mail: neuroradiology@ntlworld.com 